\title{
DISINFORMATION PROPAGATION IN SOCIAL NETWORKS AS A DIPLOMACY STRATEGY: ANALYSIS FROM SYSTEM DYNAMICS
}

\begin{abstract}
ALFREDO GUZMÁN RINCÓN
alfredo.guzman@asturias.edu.co

PhD candidate in Policy and Public Management Modelling from the Universidad Jorge Tadeo

Lozano (Colombia). Master in Engineering from the Instituto Tecnológico y de Estudios Superiores de Monterrey and Commercial Engineer from the Universidad de Ciencias Aplicadas y Ambientales U.D.C.A. Director of Research at the Corporación Universitaria de Asturias and Editorial Coordinator of Ediciones SUMMA.

\section{BELÉN RODRÍGUEZ-CÁNOVAS} brcanovas@ucm.es

$\mathrm{PhD}$ in Economics and Business Administration from ICADE. Degree in Statistics from the Complutense University of Madrid (Spain) and Bachelor's Degree in Economics and Business Administration, ICADE together with a Master's Degree in Data Mining and Business Intelligence from the Complutense University of Madrid. She is a reviewer member of the European Journal of Marketing.
\end{abstract}

\section{Abstract}

Disinformation on social media has positioned itself as a strategy of diplomacy to intervene in the decisions of sovereign states through the use of fake news, misleading content, hate speech and deliberate falsehoods, information errors, among others, in order to mobilise their citizens, and thus change both public and state policies and rulers, generate social pressure on socio-economic systems, etc. Having said that, the analysis of this strategy in terms of the process of disinformation propagation has been characterised as biased as it involves multiple actors with different levels of decision-making; hence the aim of this paper is to analyse the propagation of disinformation as a diplomatic strategy in social networks through a systemic approach. The results show a generalist model of causal loops, which provides evidence of how disinformation is disseminated, based on the various elements documented in the literature on this diplomatic strategy. Concluding on the potential nature of disinformation and the role that the state and the social networks themselves should play in preventing and mitigating this phenomenon, which is currently affecting nations across the board and which has become popular through the use of diplomatic agents.

\section{Keywords}

Disinformation, diplomacy, model, system dynamics.

\section{How to cite this article}

Rincón. Alfredo Guzmán; Rodríguez-Cánovas, Belén. Disinformation propagation in social networks as a diplomacy strategy: analysis from system dynamics. Janus.net, e-journal of international relations. Thematic dossier International Relations and Social Networks, July 2021. Consulted [online] on date of last visit, https://doi.org/10.26619/1647-7251.DT21.3

Article received on December 22, 2020 and accepted for publication on March 23, 2021

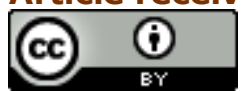




\title{
DISINFORMATION PROPAGATION IN SOCIAL NETWORKS AS A DIPLOMACY STRATEGY: ANALYSIS FROM SYSTEM DYNAMICS ${ }^{1}$
}

\author{
ALFREDO GUZMÁN RINCÓN \\ BELÉN RODRÍGUEZ-CÁNOVAS
}

\section{Introduction}

Social networks have been conceptualised as the spaces which allow interaction between online users, and whose main purpose is to facilitate the exchange of information and to encourage collective discussion among a group of interconnected contacts (Forteza, 2012). That said, in recent years this means has become the most direct mediator of relations between governments and citizens (Jahng, 2021; Lazer et al., 2018), because it allows the circulation of information of a massive nature, as well as debate about it (Carlo Bertot et al., 2012). Consequently, this has resulted in a new scenario of two-way communication that significantly affects the way in which the communication process between states and their stakeholders has been conducted (Guzmán et al., 2020).

In this scenario, diplomacy has not been an exception to the changes generated by the implementation of this communication channel, which has led to closer contact between the international agent and the local recipient of the information. (Cull, 2019; Graffy, 2009), and, which has resulted in a wide variety of benefits among which stand out, firstly, the creation of loyal communities due to the approach with foreign citizens (Graffy, 2009); secondly, the decrease in communication costs, since they are usually lower than other traditional means such as the press or television (Rashica, 2018); thirdly, the development of more effective communications with citizens due to the variety of content that can be generated in such a network such as videos, 3D photos, images, web publications, etc. (Gebhard, 2017); among others.

However, despite the benefits of the use of these networks in the context of diplomacy, some states have made use of this communication channel to propagate disinformation, understood as any deviant or untruthful information intended to mislead a target audience (Innes, 2020), with the aim of meddling in the decisions of sovereign governments by influencing the opinion of citizens, in order to fulfil some of their international policy purposes (Lazer et al, 2018; Cull, 2016).

Thus, in recent years the use of disinformation as a strategy of diplomacy in this area has become more common. An example of this was the Lisa Affair case, documented by

1 Translation by Cecilia Carabaja 
La Cour (2020), in which a group of Middle Eastern migrants were accused of raping a woman of German-Russian origin through a video on social networks. This situation led to anger and internal debate among German citizens about the state policy on immigration and refugees, provoking mass demonstrations against Muslim populations in that country. However, this turned out to be false and directed by the Russian government, with the aim of causing riots and reducing the German government's support for migrants and refugees from the Middle East.

Another example was the Russian interference in the US elections in 2016, where systematic disinformation campaigns were used to influence the opinion of the US electorate, allowing Donald Trump to win the presidency. (Office of the Director of National Intelligence, 2017). More recently, and stemming from COVID-19, the Russian and Chinese governments have been accused of systematic misinformation about the pandemic. As Milosevich-Juaristi (2020) identified in the way the Russian media RT and Sputnik reported the origin of the virus, claiming that it had been created in NATO laboratories, or that the United States had created it to destabilise the Chinese economy, such disinformation sought to create panic and confusion in order to prevent people from accessing accurate information about the virus and public health provisions. Such disinformation sought to generate panic and confusion in order to prevent people from accessing accurate information about the virus and public health provisions, which may have led to some extent to the high levels of disease in Europe and the US.

Taking these examples as a reference, and others documented by multiple authors (e.g. Fjällhed, 2020; Lanoszka, 2019), the use of this strategy has regained importance today, more than for the channel or the message itself, it has done so because of its capacity for mass propagation and the impact it can have on citizens, which is why disinformation as a strategy of diplomacy has become one of the main problems in the defence of states (Pamment et al., 2017). Hence the importance of studying this strategy and its effects. However, previous research has focused on understanding the use of this strategy and its consequences, rather than its propagation (Fjällhed, 2020). This is largely due to the difficulty of tracing the origin of this type of information, as well as the complexity of the relationships between the actors involved in its dissemination.

Taking into consideration what was previously explained, this article aimed to analyse the spread of disinformation as a diplomatic strategy on social media through a systemic approach. It is structured in four sections. The first presents the theoretical framework and the background to the problem under study; the second, the methodology used; the third, the results of the research; and the fourth, the conclusions.

\section{Diplomacy}

The meanings of diplomacy have been characterised by being broad and having diverse epistemological and methodological frameworks (Hart and Siniver, 2020), which is why it is considered a dynamic field of study, in which a single, multifunctional definition is useless, especially in the current disruptive scenario in which international relations have gone from being a private act between governments to a public act, involving the general public. 
That said, this article frames diplomacy as a systematised process in which international actors seek to achieve foreign policy objectives (Cull, 2019; Cull, 2016), through mechanisms not related to warfare, but rather through a series of actors charged with managing the international approach (Cull, 2008). These actors can be a state, a multinational, a non-profit organisation, or any actor on the global stage.

In this context, diplomacy takes on two connotations, as Cull (2008) argues. The first refers to traditional diplomacy in which actors try to manage the international environment by means of a specific commitment or pact with their counterparts, usually of a private nature; and the second, which corresponds to public diplomacy in which the state and international actors manage their environment through the commitment of foreign citizens. Thus, the use of social networks is part of the latter type of diplomacy.

Public diplomacy has thus been characterised by its methods of operation, which seek to influence public opinion by communicating with the other. Thus, multiple authors argue that in this respect, states strive to promote their interests to the citizens of another nation in order to achieve their foreign policy objectives. (Pratkanis, 2009; Potter, 2002). It is in this promotion of interests that this type of diplomacy makes use of the mass media to influence a much wider public and in which the use of social networks has a place. (Pajtinka, 2019).

In this context, and as a result of the evolution of public diplomacy in the 21st century, this has presented a series of twists and turns, which have allowed the consolidation of disinformation in social networks as a strategy of diplomacy. These changes include: the democratisation of diplomatic agents; the new communication mechanisms used in the framework of diplomacy, especially the web and social networks; the consolidation of globalised information; among others. (Fjällhed, 2020; Cull, 2019; Cull, 2008; Melissen, 2005).

\section{Disinformation as a strategy of diplomacy}

Before referring to disinformation as a strategy, it is necessary to clarify the concept of strategy. Thus, nowadays it is often referred to in multiple fields, including business, religion, culture, politics, among others (Contreras, 2013), so diplomacy is no exception. That said, in the context of this article, strategy is understood as a series of actions carried out by an agent of diplomacy to fulfil a state's foreign policy objectives. This definition is based on Cull $(2019,2008)$ and Fjällhed (2020).

In this context, disinformation as a strategy of diplomacy aims at the deliberate dissemination of false information with the objective of unbalancing foreign governments by confusing and deceiving their citizens (Gerrits, 2018; Lazer et al., 2018), whereby the sender of the message seeks to benefit from the social disagreement generated, change state policies, as well as increase its international presence and fulfil its foreign policy objectives (Cull, 2016).

Although one might think that disinformation has only recently been used by states as a strategy of diplomacy, it dates back to the end of the First World War, when it was used to influence the positioning of the political and economic system of capitalism and socialism in many nations. (Gerrits, 2018). This first stage of disinformation, which could be called "before the internet", was characterised using traditional channels such as 
television, radio, newspapers, flyers, etc. However, because of the evolution of the strategy, it has been incorporated into the internet and social media, which has meant an increase in its potential, giving rise to the era of the "digitalisation" of disinformation. This change of means derives from the mechanisms that social networks possess, which allow the message to be amplified, such as bots, trolls, echo chambers, organic and paid reach, etc., resulting in a greater exposure of citizens to disinformation. (Bjola, 2018).

In this context, the study of disinformation as a strategy of social media diplomacy has gained interest in recent years, both by governments and the academic community. Thus, studies have concentrated on case studies seeking to understand the use of such a strategy and its consequences, especially the strategies implemented by Russia and China. (ex.: La Cour, 2020; Lupion, 2018; Kania and Costello 2018), due to the difficult relations with Western countries. Such studies have highlighted the ability to interfere in democratic processes such as elections and state powers (La Cour, 2020; Bayer et al., 2019); the polarisation of citizens' opinion through the exacerbation of radical and supremacist thinking (Faris et al., 2017); and the loss of credibility of the media (Bennett and Livingston, 2018).

Despite the progress made, the difficulty in analysing this strategy of diplomacy is acknowledged and has limited the scope of action of researchers to the identification of case studies, due to the challenge of tracing the origin of disinformation, which makes it impossible to attribute and study from the origin of the message (Gerrits, 2018). It is therefore necessary to explore other aspects of this strategy, such as the propagation of disinformation, building on existing theory and thus clarifying other aspects that have not been addressed.

\section{Methodology}

\section{Aims of the study}

To achieve the objective of this study, which is to analyse the propagation of disinformation as a diplomatic strategy in social networks, the following specific objectives were set out:

1. To identify the actors and mechanisms involved in this social media diplomacy strategy.

2. To establish how these actors and mechanisms relate to each other in the propagation of disinformation on social media as a strategy of diplomacy.

3. To provide a model of causal loops that explains how this strategy of diplomacy operates.

\section{Methods and approaches}

With the purpose of fulfilling the proposed objective and specific objectives, a multidisciplinary approach was chosen, which encompassed diplomatic studies and strategy theory. Thus, on the diplomatic studies side, the main references were Der Derian (1987), Murray (2008) and Sharp (2009), while in the case of strategic theory Chamberlain (2010). These theoretical references have diplomacy, politics, and conflict 
as their intercepts, so the approach to disinformation in social networks was in line with both theoretical currents. However, to unify the perspectives of the aforementioned approaches, systems thinking was used, given the potential of this type of modelling to establish the causes and feedback of phenomena based on the elements that make up a system (Richmond, 2001), which allows for a complete understanding of its behaviour based on the conceptual delimitation and approximations made by the modeller. Thus, the causal loop diagram (CLD) was used as a modelling method.

In this context, the study followed a qualitative approach, starting with a review of the literature, which sought to identify the elements and relationships between the elements of the system that make up the strategy of disinformation in social networks from diplomacy, so previous research in the field of international relations was traced, which allowed us to understand how disinformation spreads, this being the basis for the development of the model. In this sense, an integrative approach was used for this review in order to synthesise the literature on the subject under study (Torraco, 2005).

The decision to use this type of review arose because of the emerging research topic itself, which breaks with traditional approaches to the study of diplomacy and social networks. Thus, Snyder (2019) highlights the role of this type of literature review in the development of initial or preliminary theoretical models, rather than revising old models, and where the aim is not an exhaustive review of previous studies, but the combination of perspectives for the construction of a new one. Although it does not require a specific process like the systematised reviews (Torraco, 2005), the following phases were followed for its execution:

1. The articles were searched for in SCOPUS and WOS, as well as in Google Scholar, using keywords such as disinformation, social networks, diplomacy, international relations, fake news, case studies, among others; this phase was carried out in both Spanish and English.

2. With the documents found, we proceeded to identify the elements involved in misinformation and the relationship between them.

3. With the findings, a synthesis of the information found was made, making use of the inductive method and reference tables in which information such as the objective, the methodology used, the main findings, the actors of diplomacy, etc. was located.

However, regarding the development of the CLD, the findings of the literature review were used to establish the feedback loops and balance of the disinformation system as a strategy of diplomacy. For this, the procedure established by Richardson and Pugh (1981) as well as Kim (1992) was executed as showed in the summary below.

1. The assignment of variable names (elements), the possible relationships between them and their directionality was carried out.

2. The potential adverse effects related to the construction on the CLD were identified.

3. Causal loops were classified according to their nature as either feedback (R) or balance (B).

4. The loops created were revised to be as specific as possible. 
Finally, the computational work on the model was developed in Stella Architect Software version 1.9.5.

\section{Results}

Considering the advances from previous studies, models of disinformation propagation have focused on other areas of knowledge not directly related to diplomacy, so the construction of these models lacks some elements that are incorporated in the use of this strategy by governments, which causes the overall behaviour of the propagation system to vary, as represented in Figure 1, in the feedback and balance loops defined.

Said that, it is necessary to remember that disinformation is intentional in nature (Gerrits, 2018), so its use in diplomacy is planned, which leads to the development of a strategy to maximise the effects of the message (Vosoughi et al., 2018). Thus, social media accounts created by government agencies seek to attract the largest possible target population (Hollenbaugh and Ferris, 2014) and therefore use organic, paid and invitationonly outreach to attract the largest possible audience and turn them into the disinformation susceptible population (SP) (B1) (Buchanan and Benson, 2019), who are the people who will view the disinformation and interact with it. In this sense, it is recognised that the organic reach of disinformation accounts will decrease as the susceptible population increases (B2).

By linking the SP to the social media accounts of the disinformation agent, disinformation is propagated using organic reach (Buchanan and Benson, 2019), paid reach (Helmus et al., 2018), bots (Helmus et al., 2018; Office of the Director of National Intelligence, 2017) and trolls (Starbird, 2019), with the aim of systematically exposing the SP to the message, and thus consolidating the disinformed population (DP) (B3). This is synthesised in the visualisations of the message, to ultimately decrease the population susceptible to misinformation. Taking the latter into consideration, the incorporation of organic and paid reach is derived from the dynamics of the social network, especially the algorithm, since through these elements the message can be displayed under the conditions of use of the communication channel, however, as the number of uninformed people grows, the effect of organic reach will be less (B4). Whereas bots and trolls are used to amplify the message outside the conditions of the platform. These two elements were incorporated in the Russian interference in the US elections, where they were used to amplify the disinformation message (Helmus et al., 2018). in concordance with what previously stated, and from a more holistic view of the case of the US elections, it was detected how the IRA group (belonging to a Russian agency) had African-American populations as its disinformation audience, in which after consolidating the SP it proceeded to pay for disinformation content (representing $66 \%$ of the activity), as well as bots and trolls, resulting in disinformation on the Facebook social network alone of $11,200,000$ people (Office of the Director of National Intelligence, 2017). 
Figure 1. Diagram of causal loops of disinformation as a strategy of diplomacy.

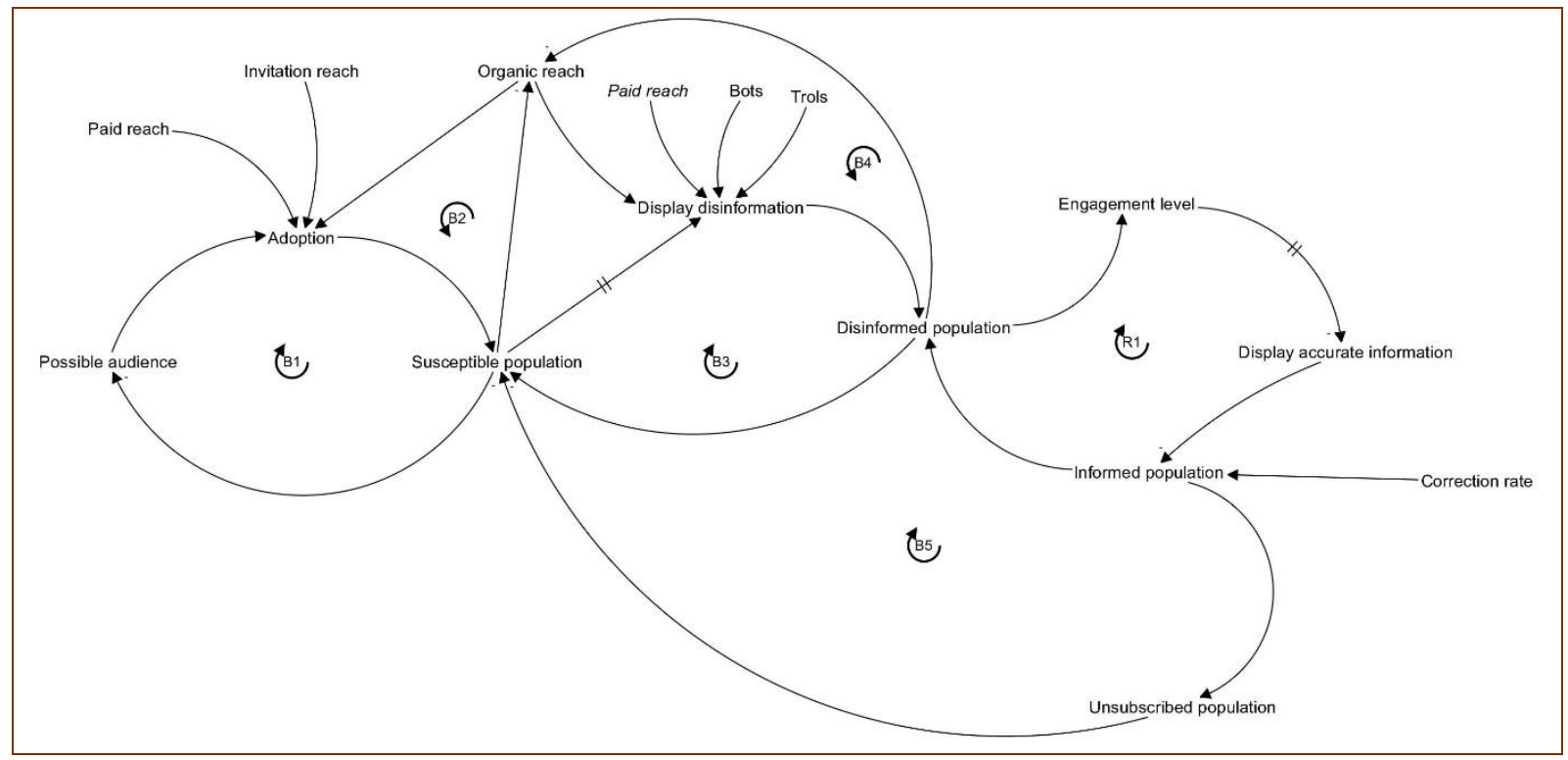

Source: Own preparation

However, the PD is involved in a systematic exposure to misinformation, so that by interacting with the various misinforming messages, the echo chamber effect is generated in which the ideas and beliefs resulting from the exposure to misinformation are amplified due to the repetition of the same or similar content, which reinforces the misinforming message (Bessi et al., 2015; Garrett, 2009). This leads to the existence of a higher level of engagement on false information, representing for the DP the difficulty of accessing truthful information, which means that the informed population (IP) is low (R1) (Quattrociocchi et al., 2016), consolidating one of the ultimate aims of disinformation as a strategy of diplomacy. Finally, the individual's ability to seek additional information, usually from media such as television, radio, and the press, is recognised as a final element, leading to a correction rate that results in a decrease in PD (Chiang and Knight, 2011; Entman, 2007). Hence, the IP must make the decision not to engage with the disinforming agent, by ceasing to follow the disinforming account, or to continue its relationship and remain part of the SP (B5).

\section{Conclusions}

Several conclusions have been reached in this study. The first is the fulfilment of the general objective, which was to analyse the spread of disinformation as a diplomatic strategy in social networks, through a systemic approach. Thus, it must be recognised that disinformation because of diplomacy strategy is a complex phenomenon in which various elements interact, which are arranged by both the disinforming agent and the social networks. Considering the latter, the proposed model allows us to recognise through the establishment of dynamic hypotheses (causal loops) the way in which disinformation spreads in this communication channel. In this scenario, the study 
constitutes a first precedent for the systemic analysis of disinformation as a strategy of diplomacy, given that the advances developed have concentrated on case studies and on the effect of its use on citizens, so that both the model proposed, and the review carried out provide researchers with new tools for understanding this phenomenon.

With respect to the model proposed, it was possible to define the mechanisms that the disinforming agent must contact the $\mathrm{PO}$, which are not necessarily the same as those used to disinform. An example of this are the bots and trolls that, given the cost they represent, are used to propagate the message in the SP and thus disinform. Subsequently, the way in which the message is propagated through its visualisation was identified. In turn, it is the citizen or user of the network who decides whether to interact with the publication to reaffirm their ideals and beliefs. It is in this aspect where the algorithm of the social network begins to create an echo chamber that prevents the visualisation of truthful information, making it difficult to create an IP and counteract disinformation.

This model reaffirms the potential of social networks to misinform, in this case through diplomacy, so that both states and the managers of these networks should focus their efforts on defining effective mechanisms for the prevention and mitigation of this phenomenon, based on an understanding of the elements involved in this strategy, as well as the systemic approach presented in this paper. Finally, for future research, it is suggested that dynamic models be developed to configure patterns of how it propagates, as well as to evaluate the role of the elements and their impacts.

\section{References}

Bayer, J., Bitiukova, N., Bard, P., Szakács, J., Alemanno, A. y Uszkiewicz, E. (2019). Disinformation and Propaganda - Impact on the Functioning of the Rule of Law in the EU and Its Member States, SSRN Scholarly Paper No. ID 3409279. Social Science Research Network, Rochester, NY, available at: https://papers.ssrn.com/abstract $=3409279$ (accessed 23 March 2021).

Bennett, W.L. y Livingston, S. (2018). The disinformation order: Disruptive communication and the decline of democratic institutions. European Journal of Communication, Vol. 33 No. 2, pp. 122-139.

Bessi, A., Zollo, F., Del Vicario, M., Scala, A., Caldarelli, G. y Quattrociocchi, W. (2015). Trend of Narratives in the Age of Misinformation. PloS One, Vol. 10 No. 8, p. e0134641.

Bjola, C. (2018). The Ethics of Countering Digital Propaganda. Ethics y International Affairs, Vol. 32 No. 3, pp. 305-315.

Buchanan, T. y Benson, V. (2019). Spreading Disinformation on Facebook: Do Trust in Message Source, Risk Propensity, or Personality Affect the Organic Reach of 'Fake News'? Social Media + Society, Vol. 5 No. 4, p. 1-9

Carlo Bertot, J., Jaeger, P.T. y Grimes, J.M. (2012). Promoting transparency and accountability through ICTs, social media, and collaborative e-government (edited by $\mathrm{Ae}$ Chun, S). Transforming Government: People, Process and Policy, Vol. 6 No. 1, pp. 7891. 
Chamberlain, G.P. (2010), Understanding Strategy. CreateSpace: Charleston.

Chiang, C.-F. y Knight, B. (2011). Media Bias and Influence: Evidence from Newspaper Endorsements. The Review of Economic Studies, Vol. 78 No. 3, pp. 795-820.

Contreras, E.R. (2013). El concepto de estrategia como fundamento de la planeación estratégica. Pensamiento \& Gestión, no. 35, pp. 152-181.

Cull, N.J. (2008). Public Diplomacy: Taxonomies and Histories. The Annals of the American Academy of Political and Social Science, vol. 616, no. 1, pp. 31-54.

Cull, N.J. (2016). Engaging foreign publics in the age of Trump and Putin: Three implications of 2016 for public diplomacy. Place Branding and Public Diplomacy, Vol. 12 No. 4, pp. 243-246.

Cull, N.J. (2019). Public Diplomacy: Lessons from the Past, 2009, 1st ed., Figueroa Press, Los Angeles.

Der Derian, J. (1987), On diplomacy: a genealogy of Western estrangement, 1st ed., Blackwell, Oxford.

Entman, R.M. (2007). Framing Bias: Media in the Distribution of Power. Journal of Communication, Vol. 57 No. 1, pp. 163-173.

Evan, P. (2002). Canada and the New Public Diplomacy. International journal (Toronto), vol. 58, no. 1, pp. 43-64.

Faris, R.M., Roberts, H., Etling, B., Bourassa, N., Zuckerman, E. and Benkler, Y. (2017). Partisanship, Propaganda, and Disinformation: Online Media and the 2016 U.S. Presidential Election. [23 March 2021]. Available at: https://dash.harvard.edu/handle/1/33759251

Fjällhed, A. (2020). Managing Disinformation Through Public Diplomacy in Fitzpatrick, K. and Seib, P. (Eds.), Public Diplomacy and the Politics of Uncertainty, 1st ed., Springer International Publishing, Nueva York, pp. 227-253.

Forteza, M. (2012). El papel de los museos en las redes sociales. Biblios: Journal of Librarianship and Information Science, No. 48, pp. 31-40.

Garrett, R.K. (2009). Echo chambers online? Politically motivated selective exposure among Internet news users. Journal of Computer-Mediated Communication, Vol. 14 No. 2, pp. 265-285.

Gebhard, C. (2017). International Relations in McGlinchey, S. (Ed.), One World, Many Actors, 1st ed., E-International Relations Publishing, Bristol, pp. 32-45.

Gerrits, A.W.M. (2018). Disinformation in International Relations: How Important Is It? Security and Human Rights, Vol. 29 No. 1-4, pp. 3-23.

Graffy, C. (2009). Public Diplomacy: A Practitioner's Perspective. American Behavioral Scientist, Vol. 52 No. 5, pp. 791-796.

Guzmán, A., Rodríguez-Cánovas, B., Valencia, L.I. and Zarama, D.A. (2020). Comunicación de las políticas públicas en redes sociales: caso Colombia", Comunicación especializada: historia y realidad actual, McGraw-Hill Interamericana de España, pp. 783-802. 
Hart, D. y Siniver, A. (2020). The Meaning of Diplomacy. International Negotiation, pp. $1-25$.

Helmus, T.C., Bodine-Baron, E., Radin, A., Magnuson, M., Mendelsohn, J., Marcellino, W., Bega, A., et al. (2018). Russian Social Media Influence: Understanding Russian Propaganda in Eastern Europe, RAND Corporation, Washington.

Hollenbaugh, E.E. y Ferris, A.L. (2014). Facebook self-disclosure: Examining the role of traits, social cohesion, and motives. Computers in Human Behavior, Vol. 30, pp. 50-58.

Innes, M. (2020). Techniques of disinformation: Constructing and communicating 'soft facts' after terrorism. The British Journal of Sociology, Vol. 71 No. 2, pp. 284-299.

Jahng, M.R. (2021). Is Fake News the New Social Media Crisis? Examining the Public Evaluation of Crisis Management for Corporate Organizations Targeted in Fake News. International Journal of Strategic Communication, Vol. 15 No. 1, pp. 18-36.

Kania, E.B. y Costello, J.K. (2018). The Strategic Support Force and the Future of Chinese Information Operations. The Cyber Defense Review, Vol. 3 No. 1, pp. 105-122.

Kim, D. (2016). Guidelines for Drawing Causal Loop Diagrams, The Systems Thinker, 23 February. [23 March 2021]. Available at: https://thesystemsthinker.com/guidelines-fordrawing-causal-loop-diagrams-2/

la Cour, C. (2020). Theorising digital disinformation in international relations. International Politics, Vol. 57 No. 4, pp. 704-723.

Lanoszka, A. (2019). Disinformation in international politics. European Journal of International Security, Vol. 4 No. 2, pp. 227-248.

Lazer, D.M.J., Baum, M.A., Benkler, Y., Berinsky, A.J., Greenhill, K.M., Menczer, F., Metzger, M.J., et al. (2018). The science of fake news. Science, Vol. 359 No. 6380, pp. 1094-1096.

Lupion, M. (2018). The Gray War of Our Time: Information Warfare and the Kremlin's Weaponization of Russian-Language Digital News. The Journal of Slavic Military Studies, Vol. 31 No. 3, pp. 329-353.

Melissen, J. (2005), The New Public Diplomacy. Palgrave Macmillan: London.

Milosevich-Juaristi, M. (2020). ¿Por qué hay que analizar y comprender las campañas de desinformación de China y Rusia sobre el COVID-19? Real Instituto El Cano. [24 March 2021]. Available at: http://www.realinstitutoelcano.org/wps/portal/rielcano es/contenido?WCM GLOBAL C ONTEXT=/elcano/elcano es/zonas es/ari-58-2020-milosevich-analizar-y-comprendercampanas-desinformacion-china-rusia-covid-19

Murray, S. (2008). Consolidating the Gains Made in Diplomacy Studies: A Taxonomy. International studies perspectives, vol. 9, no. 1, pp. 22-39.

Office of the Director of National Intelligence. (2017). Assessing Russian Activities and Intentions in Recent US Elections, Informit Analysis and Policy Observatory (APO), Washington D.C. [23 March 2021]. Available at: https://www.dni.gov/files/documents/ICA 2017 01.pdf 
Pajtinka, E. (2019). Public diplomacy as a theoretical problem: searching for a definition. EJTS European Journal of Transformation Studies, vol. 7, no. 2, pp. 21-32.

Pamment, J., Olofsson, A. y Hjorth-Jenssen, R. (2017). The response of Swedish and Norwegian public diplomacy and nation branding actors to the refugee crisis. Journal of Communication Management, Vol. 21 No. 4, pp. 326-341.

Pratkanis, A. (2008). Public Diplomacy in International Conflicts in Routledge Handbook of Public Diplomacy Routledge, Abingdon UK.

Quattrociocchi, W. (2016). Echo Chambers on Facebook, Harvard. [23 March 2021]. Available at: http://www.law.harvard.edu/programs/olin center/papers/pdf/Sunstein 877.pdf.

Rashica, V. (2018). The Benefits and Risks of Digital Diplomacy. SEEU Review, Vol. 13 No. 1, pp. 75-89.

Richardson, G.P. y Pugh, A.L. (1981). Introduction to System Dynamics Modeling with DYNAMO, Productivity Press, Cambridge.

Richmond, B. (2001). An Introduction to Systems Thinking, 1st ed. Isee systems: Lebanon.

Sharp, P. (1999). For Diplomacy: Representation and the Study of International Relations. International Studies Review, vol. 1, no. 1, pp. 33-57.

Snyder, H. (2019). Literature review as a research methodology: An overview and guidelines. Journal of Business Research, Vol. 104, pp. 333-339.

Starbird, K. (2019). Disinformation's spread: bots, trolls and all of us. Nature, Vol. 571 No. 7766, pp. 449-449.

Torraco, R.J. (2005). Writing Integrative Literature Reviews: Guidelines and Examples. Human Resource Development Review, Vol. 4 No. 3, pp. 356-367.

Vosoughi, S., Roy, D. and Aral, S. (2018). The spread of true and false news online. Science, Vol. 359 No. 6380, pp. 1146-1151. 